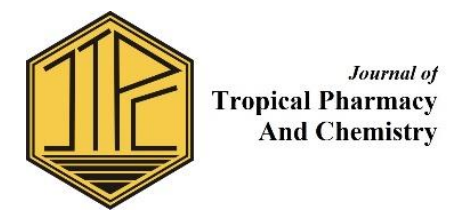

\title{
SCREENING OF ACTIVE COMPOUNDS FROM Artemisia annua USING HFC- 134A SUBCRITIC EXTRACTION SYSTEM
}

\author{
Arthur Lelono*, Sabar Simanungkalit, Ibnu Umarudin, Herlan Herdiawan \\ Research Center for Chemistry, Indonesian Institute of Science, Kawasan Puspiptek \\ Serpong - Tangerang Selatan \\ *Corresponding author: aalelono@gmail.com
}

\begin{abstract}
Artemisia апnиa is known as the source of artemisinin, a sesqueterpene lactone possessing endoperoxide moeity with antiplasmodium activity. Sub-critical extraction of artemisinin from Artemisia annua using R134a solvent was conducted. A close system cycle process was constructed to investigate the ability of R134a to extract artemisinin together with other active compounds. Artemisinin and other isolated compouds yield was investigated at $30^{\circ} \mathrm{C}$ and presure process at 10 barr, with variation of process time. The extracted product was analysed as artemisinin as the target compounds with several isolated compounds as by product. Artemisinin content was reported ranging up to $0,5 \%$, and the sub critic system was reported to be more efficient and effective comparing to other conventional extraction methods. The phytonics HFC-134a sub critics process can be used for extraction in selected pharmacologically active products from herbal plants.
\end{abstract}

Keywords: Artemisia annua, HFC-134a sub critic, extraction

Submitted on: 3 January 2018

Accepted on: 8 June 2018

DOI: https://doi.org/10.25026/jtpc.v4i3.149

\section{INTRODUCTION}

The quality of natural extracts and consequently their biological activity is related to their composition, and majorly dependent on the extraction procedure, the type of solvent, origin of the raw materials, its storage condition and the pre-treatment applied (Moure, 2001 \& Louili, 2004) Conventional extraction, such as soxhlet and maceration methods, often requires high quantity of organic solvents, long periods, and temperature higher than ambient, which can degrade some bioactive compounds (Pessoa, 2015). Therefore, alternative methods to extract natural bioactive substances, such as supercritical (SE) and subcritical fluid extraction (SFE), have been studied. Supercritical fluid extraction demonstrates effective method yet high in investment cost and high level of safety process limitation. In view of the economic, safety and environmental needs, subcritical extractions can be used as alternative to 
SFE, thereby allowing alternative design in the process with more reasonable costs. There are several reports regarding the extraction of natural products by subcritical water (Babu, 2014). However, reports on the R134a refrigerants as solvent in the subcritical extraction are sparse. R134a (1,1,1,2-tetrafluoroethane) is non toxic, non reactive, non flammable, and non ozone depleting. It has high volatility and boiling point at atmospheric pressure is $-25.9^{\circ} \mathrm{C}$, which mean it leaves negligible solvent residue in the products. $\mathrm{R} 134 \mathrm{a}$ is in a gas form at room temperature, also stabile to aqueous acids and bases, and immiscible with water and sparingly soluble in water $(1500 \mathrm{ppm}$ at $20^{\circ} \mathrm{C}$ ). It is normally handled as a compressed gas under pressure in liquid form and has a liquid density of about $1.3 \mathrm{~kg} / \mathrm{l}$ (Corr, 2002). There is growing interest in the use of lower boiling fluids, particularly R134a, as liquid solvents across a range of applications. The extracts obtained by R134a are generally low in color, low in inert lipid content and high in desired impact or active species with good recovery of the active ingredients from the raw material. Extraction could be conducted anywhere within the liquid temperature range of $\mathrm{R} 134 \mathrm{a}$ but is normally conducted around or below room temperature.

In the 1970s, from the plant Artemisia annua, artemisinin was discovered and extracted as a pure drug; since then the exploration and chemical synthesis of its derivates and studies on other biological activities has been carried out. The small yield of artemisinin in the plants and heat sensitive properties gives a challenging effort in the isolation process. Conventional extraction method has been reported to have high toxicity and environment issues, with non economical yield (Choursi, 2017). Many of the traditional organic solvents are under increasing regulatory pressure due to residual toxicity, whereas conventional steam distillation could affect the character of certain products through hydrolysis, thermolysis and loss of volatile compounds from the extract. Recent studies showed that R134a has potent to replace other conventional solvents in the extraction of natural flavors and pharmaceutical active compounds from plants, which also has been reported to give good result in extracting artemisin from Artemisia annua (Wilde, 2001). The process is advantageous in that the solvents can be customized: by using modified solvents with HFC134a, the process can be made highly selective in extracting a specific class of phytoconstituents. Similarly, other modified solvents can be used to extract a broader spectrum of components (Kumar, 2014). The biological products made by this process have extremely low residual solvent. The residuals are invariably less than 20 parts per billion and are frequently below levels of detection. These solvents are neither acidic nor alkaline and, therefore, have only minimal potential reaction effects on the botanical materials (Emmen, 2000). In this study, subcritical R134a extraction using 10L modified SS316 close system vessel was evaluated as alternative solid liquid extraction method of artemisinin and other compounds from Artemisia annua.

\section{MATERIALS AND METHOD}

\section{Plant Samples.}

Air dried Artemisia annua leaves were collected from Cibodas Botanical Garden, Cipanas West Java. The dried leaves were ground to $200 \mathrm{mesh}$, and kept in a seal compartment prior to extraction. The leaves were stored in storage room and extracted no more than 7 days. 


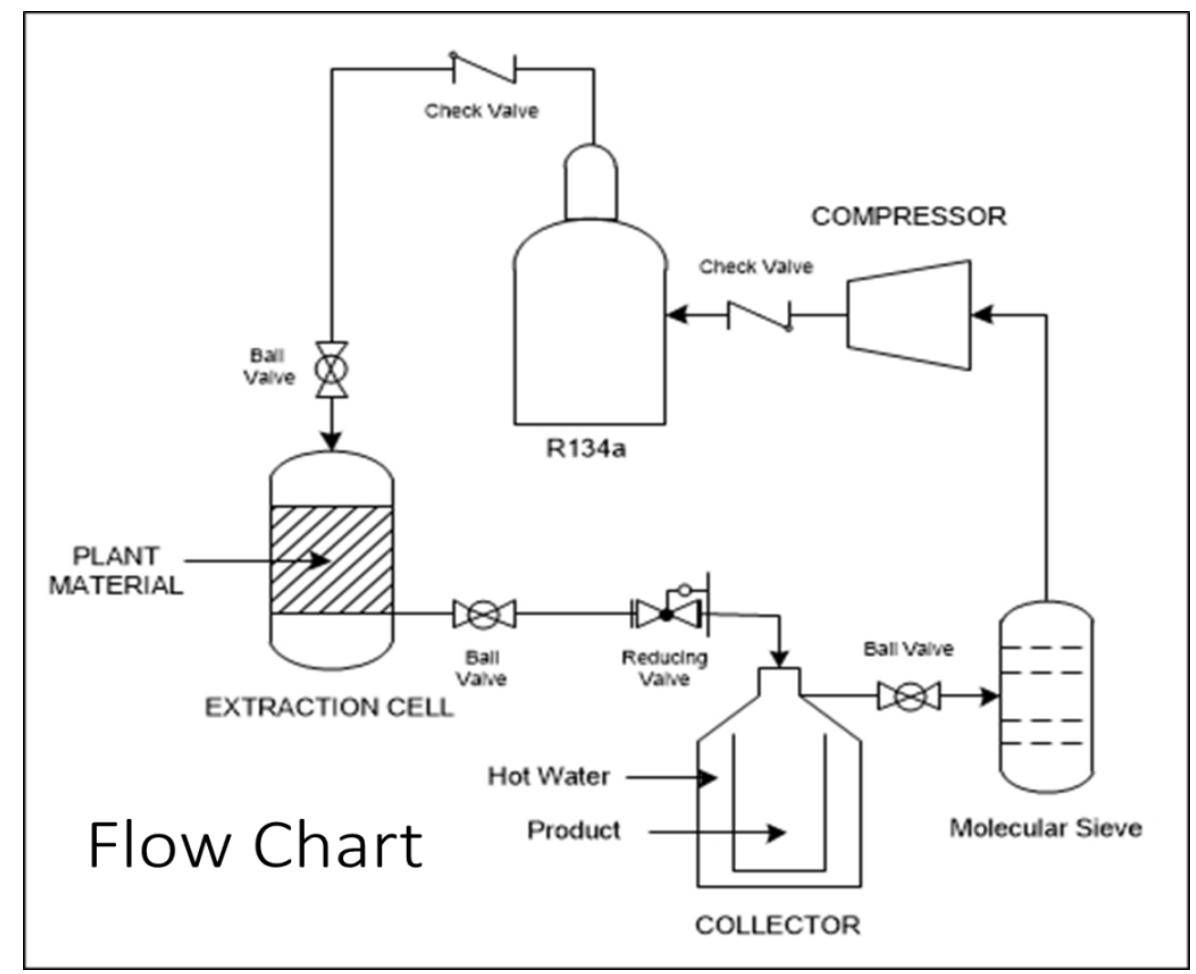

Figure 1 Schematic diagram of the HFC-134a subcritical extraction unit

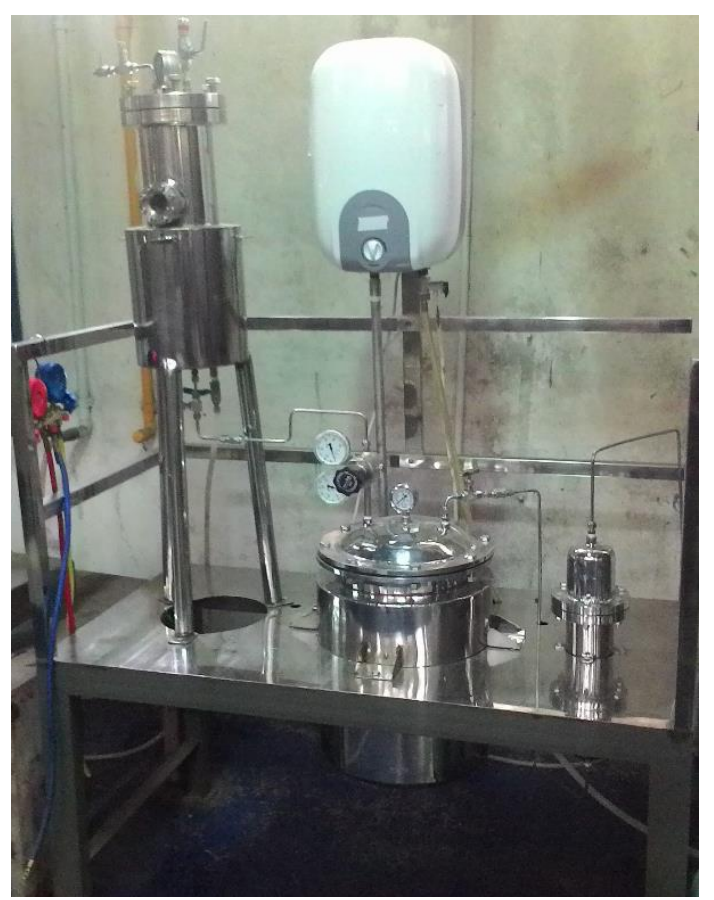

Figure 2 Subcritical HFC-134a extraction unit system 


\section{Subcritical R134a Extraction of Artemisia annua.}

All of the extraction experiments were conducted on a self-designed instrument. The schematic diagram of the HFC-134a subcritical extraction early state unit used in the present study and pictorial view are shown in Figure 1 and Figure 2 respectively. The unit consists of a 5L extraction vessel, a 20L of collector vessel, compressor and heat exchanger unit, and 1 filtration system. All vessels are constructed with SS316, and designed to hold pressure up to 40barr. Water bath heating mantle was constructed to obtained adequate temperature in the collector vessel to maximize the HFC134a transfer rate of liquid to gas state.

Artemisia annua ground air dried leaves measuring 250 gram were subjected to HFC-134a subcritical extraction under room temperature. The unit was operated under various operating conditions to determine the effects parameter such as pressure of solvent during process, time process and ratio between HFC-134a and plants samples on yield percentage of the products.

\section{Characterization of extraction products}

Chromatography method was conducted prior to the characterizations of products obtained from HFC-134a subcritical extraction of Artemisia annua. TLC and HPLC analysis of crude extract product was conducted for preliminary analysis. Comparison of artemisinin standard was used as a guided fractionation. Purification was conducted using flash column chromatography, and isolated compounds molecular weight were analyzed using LC-MS.

\section{RESULT AND DISCUSSION}

\section{Subcritical R134a Extraction of Artemisia annua.}

Extraction of 250 gram air dried Artemisia annua leaves using HFC-134a subcritical system gives 1,525 gram of products. The product was observed having a dark yellow to green paste with needle like crystalline characteristic (Figure 3), is different from conventionally used organic solvent maceration method product which give dark green paste consistency. HPLC analysis and TLC chromatogram profiles indicate the presence of artemisinin in the products (Figure 4), a sesquiterpene lactone having peroxide bridge moiety as one of the target compound from Artemisia annua. Study from Lapkin (2006), reported that artemisinin has been successfully isolated from Artemisia апnиa under HFC-134a subcritical system.

The effect of extraction process time demonstrated that the product increased as time dependent. After 24 hours of extraction process, the yield product increased up to $1,63 \%$ (dry weight) from 250gram of Artemisia annua (Table 1). These results showed that the increase time contact between HFC-134a as the extraction solvent with the plant material gives direct result on how much material extracted in the extraction vessel. For further application the time process will selected at 1 hour reaction due to non effective and time consuming effort in the 24 hours process. The replication extraction at 1 hour process will meet up with the amount of product collected in 24 hours of process. 

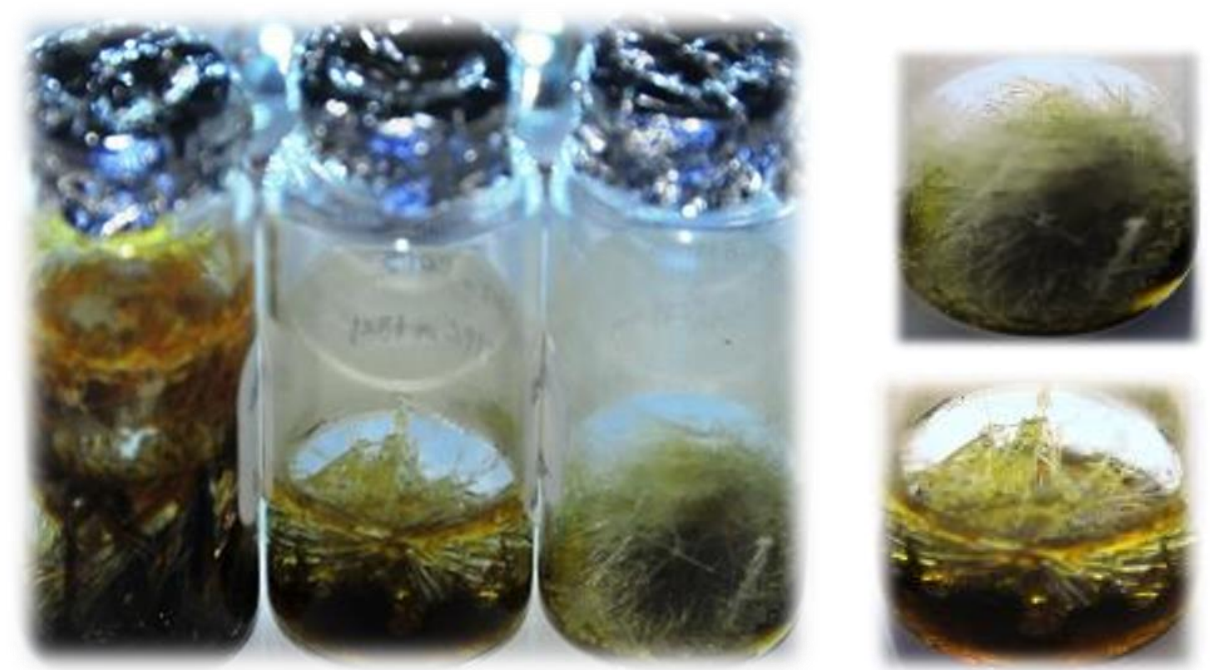

Figure 3. Product collected form extraction of Artemisia annua using HFC-134a subcritical system
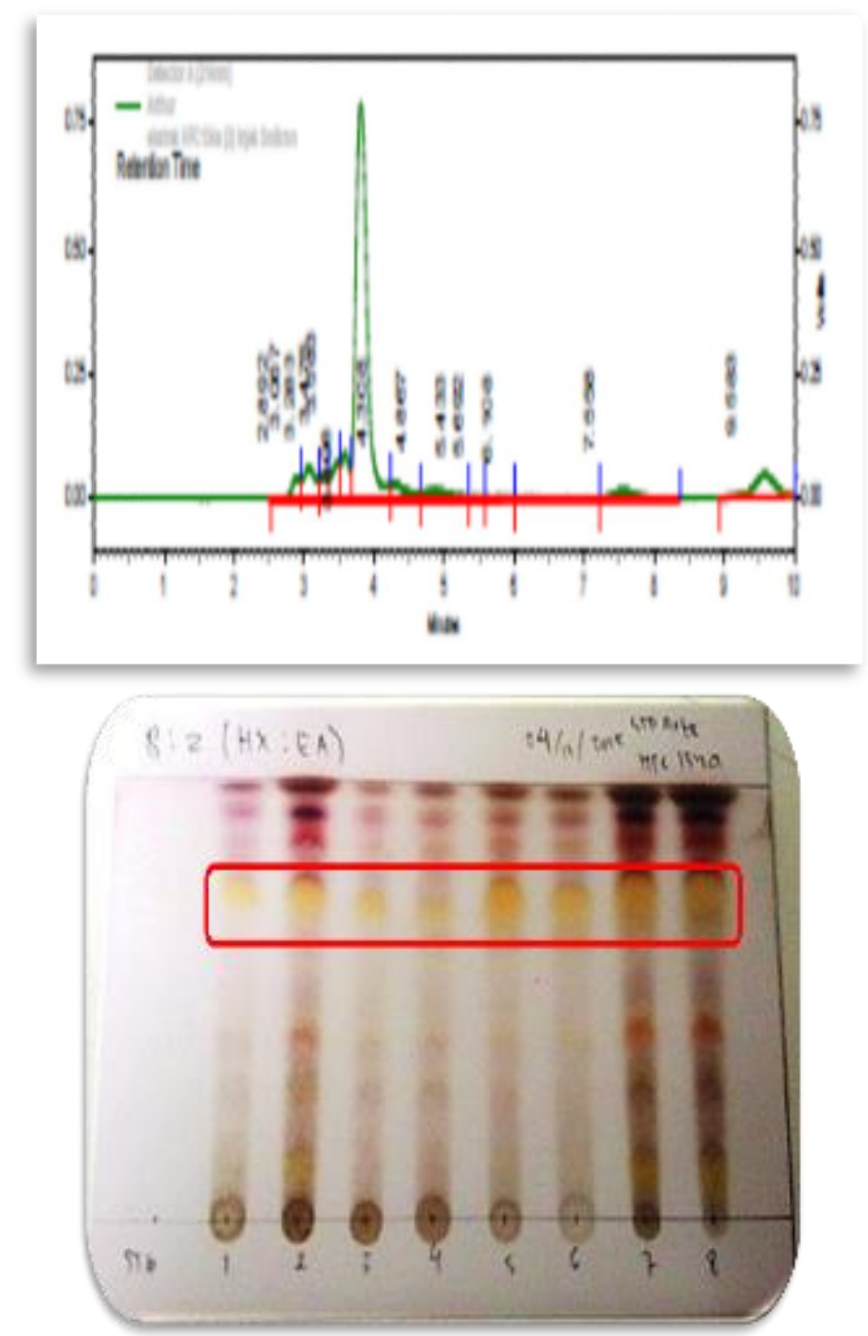

Figure 4. HPLC and TLC chromatogram from the product collected form extraction of Artemisia annua using HFC-134a subcritical system 
Table 1. Effect of process time on yield product collected form extraction of Artemisia annua using HFC-134a subcritical system

\begin{tabular}{ccccc}
\hline $\mathrm{n}$ & $\begin{array}{c}\text { Time } \\
(\text { minutes })\end{array}$ & $\begin{array}{c}\text { Plant material } \\
(\text { gram })\end{array}$ & $\begin{array}{c}\text { Product Extract } \\
\text { Weight }(\text { gram })\end{array}$ & $\begin{array}{c}\text { Product Yield } \\
(\mathrm{D} . \mathrm{W})(\%)\end{array}$ \\
\hline 1 & 90 & 250 & 1.525 & 0,61 \\
2 & 180 & 250 & 2.025 & 0,81 \\
3 & 360 & 250 & 2.529 & 1,01 \\
4 & 720 & 250 & 3.072 & 1,23 \\
5 & 1440 & 250 & 4.076 & 1,63 \\
\hline
\end{tabular}

Table 2. Effect of HFC-134a and pressure on yield product collected form extraction of Artemisia annua using HFC-134a subcritical system

\begin{tabular}{ccccc}
\hline $\mathrm{n}$ & $\begin{array}{c}\text { Plant material } \\
(\text { gram})\end{array}$ & $\begin{array}{c}\text { HFC-134a } \\
\text { Used (gram })\end{array}$ & $\begin{array}{c}\text { Release } \\
\text { Pressure (barr) }\end{array}$ & $\begin{array}{c}\text { Product Weight } \\
\text { Extract (gram) }\end{array}$ \\
\hline 1 & 250 & 2500 & 1 & 1,612 \\
2 & 250 & 2500 & 1 & 1,232 \\
1 & 250 & 2500 & 2 & 1,411 \\
2 & 250 & 2500 & 2 & 1,012 \\
1 & 250 & 2500 & 4 & 1,711 \\
2 & 250 & 2500 & 4 & 1,143 \\
1 & 250 & 1250 & 1 & 0,411 \\
2 & 250 & 1250 & 1 & 0,387 \\
1 & 250 & 2500 & 1 & 1,611 \\
2 & 250 & 2500 & 1 & 1,287 \\
1 & 250 & 5000 & 1 & 2,021 \\
2 & 250 & 5000 & 1 & 1,215 \\
\hline
\end{tabular}

The yield content of the product is highly influenced by the amount of HFC134a ratio to the ground Artemisia annua leaves samples, as described in Table 2. The ratio of 1:20 demonstrated to give maximum yield content compared to ratio 1:5. The higher ratio of HFC-134a is related with more fresh solvents in the extraction vessel to interact and acting as carrier solvents to extract selected compounds from Artemisia аппиа, therefore giving more yields in the extraction product. The pressure variation during the extraction process did not show significant difference in the overall yield content. Subcritical extraction release process of 1 barr pressure yields an average of $1,422 \mathrm{gram}$ of product compared to 1,427 gram under 4 barr pressures, therefore it is suitable to use the 1 barr pressure for further extraction process due to safety procedure in the extraction process. This low pressure give more advantages in handling with liquefy HFC-134a gas and safety in constructing the pilot scale unit extractors. This is the first report of process parameters in the subcritical extraction of Artemisia аппиа, using the equipment described in Figure 2. Babu et. al in 2014 reported that the increased level of pressure up to 11 barr resulted in $91 \%$ yield of turmeric oil subcritical extraction. 


\section{Characterization of extraction products}

Flash column chromatography was used for further purification of the product, yielding artemisinin and other isolated compounds. A total amount of 0,6051 gram of artemisinin crystal was isolated from 250 gram of Artemisia annua dried leaves, and was confirmed by LC-MS comparison of artemisinin commercial standard. Three other fractions above artemisinin TLC spot was collected and purified weighing at (Fraction $\mathrm{A} 1=64 \mathrm{mg})$, (Fraction $\mathrm{A} 2=$ 95,1 $\mathrm{mg}$ ), and (Fraction A3 = $328 \mathrm{mg}$ ), respectively. Each fraction were subjected for LC-MS analysis to determine their molecular weight using C-8 column [150mm $x 4.6 \mathrm{~mm}]$ coupled with $5 \mu \mathrm{L}$ injection and $0.2 \mathrm{ml} / \mathrm{min}$ flow rate of methanol. LCMS chromatogram in Figure 5 , showed the peak area, whereas in Figure 6, showed the mass fragmentation of each fraction, respectively.

Fraction A1, showed major peak at Rt 2,92 min, with some impurities still observed in the chromatogram. From the mass spectrum analysis, it showed most intense peak are $\mathrm{m} / \mathrm{z}$ 245,43 $[\mathrm{M}+\mathrm{H}]^{+}$ (Figure. 6) Fraction A2, showed two major peak area at Rt 2.88 minutes and 3.27 minutes, respectively. Peak at Rt 2.88 minutes gives base peak molecular weight $\mathrm{m} / \mathrm{z} 267,31,[\mathrm{M}+\mathrm{H}]^{+}$and it was confirmed by addition of sodium ion $\mathrm{m} / \mathrm{z} 289,29$ $[\mathrm{M}+\mathrm{Na}]^{+}$, which is also similar to the most intense peak $\mathrm{m} / \mathrm{z}$ 267,29 $[\mathrm{M}+\mathrm{H}]^{+}$in Fraction A3. From the mass spectrum analysis, the most intense peak in fraction A3, was confirmed with addition of sodium ion $\mathrm{m} / \mathrm{z} 289,29[\mathrm{M}+\mathrm{Na}]^{+}$and $\mathrm{m} / \mathrm{z}$ $559,69[2 \mathrm{M}+\mathrm{Na}]^{+}$. The peak which appears at Rt 3.27minutes of Fraction A2 gives a molecular weight $\mathrm{m} / \mathrm{z} 235,45[\mathrm{M}+\mathrm{H}]^{+}$, and it was confirmed by addition of $\mathrm{Na}^{+}$ which gives 257,48 [M+Na $]^{+}$and 491,92 $[2 \mathrm{M}+\mathrm{Na}]^{+}$. TLC colorization using anisaldehyde-sulphuric acid indicates the presence of steroids and terpenes compounds. Further identification of isolated compounds is needed to identify the isolated compounds, since this the first report of the subcritical isolation from Artemisia annua besides artemisinin as selected compound. Bhakuni, et.al reported in 2001 several compounds has been successfully isolated form Artemisia annua, specially its essential oils, and characterized a large number of monoterpenoids.

\section{CONCLUSION}

The extraction unit designed and constructed based on HFC-134a subcritical has successfully isolate artemisinin from Artemisia апnиа. Time process, pressure release and ratio between samples and HFC-134a prove to gives significant difference in the yield product. As a byproduct of artemisinin isolation, three fractions were isolated and mass spectrum analysis showed Fraction A $1 \mathrm{~m} / \mathrm{z} 245,43[\mathrm{M}+\mathrm{H}]^{+}$, Fraction A2 m/z 235,45 $[\mathrm{M}+\mathrm{H}]^{+}$, and Fraction A3 m/z $267,29[\mathrm{M}+\mathrm{H}]^{+}$. Further identification of isolated compounds is needed to identify the isolated compounds.

\section{REFERENCES}

[1]. Babu, PN, MV. Raviteja, B. Prakash, S. Bangera, Aswini, S (2014). Subcritical Extraction of Turmeric oil in a pilot plant unt using R-134a. International Journal of Natural Products Research, 4(3): 77-81.

[2]. Bhakuni R. S., D. C. Jain, R. P. Sharma and S. Kumar 2001 Secondary metabolites of Artemisia annua and their biological activity. Current Science, VOL. 80, NO. 1 pp 35-48 
[3]. Corr. S (2002). 1,1,1,2Tetrafluoroethane; from refrigerant and propellant to solvent. Journal of Fluorine Chemistry 118: 55-57

[4]. Emmen H. H., E. M. G. Hoogendijk, W. A. A. KlöppingKetelaars, H. Muijser, E. Duistermaat,J. C. Ravensberg, D. J. Alexander, D. Borkhataria, G. M. Rusch and B. Schmit, Regul. Toxicol. Pharm., 2000, 32, 22-35 (human safety and pharmacokinetics of HFC 134a)

[5]. Lapkin AA, Plucinski PK, Cutler M. 2006. Comparative assessment of technologies for extraction of artemisinin. $J$ Nat Prod. 2006 Nov;69(11):1653-64.

[6]. Louli, V. N. Ragoussis, K. Magoulas, Recovery of phenolic antioxidants from wine industry byproducts, Bioresour. Technol. 92 (2004) 201-208.

[7]. Moure, J.M. Cruz, D. Franco, J.M. Domínguez, J. Sineiro, H. Domínguez, et al., Natural antioxidants from residual sources, Food Chem. 72 (2001) 145-171.
[8]. Pessoa A. S., R. Podestá, J.M. Block, E. Franceschi, C. Dariva, M. Lanza, Extraction of pequi (Caryocar coriaceum) pulp oil using subcritical propane: Determination of process yield and fatty acid profile. J. Supercrit. Fluids, 101 (2015) 95-103.

[9]. Souhila Laboukhi-Khorsi, Kamel Daoud, and Smain Chemat (2017) Efficient Solvent Selection Approach for High Solubility of Active Phytochemicals: Application for the Extraction of an Antimalarial Compound from Medicinal Plants. ACS Sustainable Chem. Eng., 2017, 5 (5), pp 43324339.

DOI: 10.1021/acssuschemeng.7b00384

[10]. Sunil Kumar, 2014, Design And Development Of Extraction Process In The Isolation Of Phytopharmaceuticals From Plant Sources. International Journal of Medicine and Health Profession Research. 1(1), 28 - 38.

[11]. Wilde P.F., T.J. Noakes, R.L. Powell, (2001); US Patent 6224847 J.E Haworth, WO 0126472

How to cited this article :

Lelono, A., Simanungkalit, S., Umarudin, I., Herdiawan, H., 2018. Screening of Active Compounds from Artemisia annua using HFC-134a Subcritic Extraction System, J. Trop.Pharm. Chem. 4(3); 114-121. 